\title{
Research and modeling of the hydrodynamic characteristics of the modified valve
}

\author{
(C) Arthur I. Nurmukhametov, ${ }^{1+}$ Arnold Sh. Bicbulatov, ${ }^{2} *$ and Anton A. Nazarov ${ }^{1}$ \\ ${ }^{1}$ Department of Chemical Production Machines and Apparatuses. Kazan National Research Technological \\ University. Karl Marx St., 68. Kazan, 420029. Tatarstan Republic. Russia. \\ Phone:+7 (843) 231-43-63.E-mail:mahp_kstu@mail.ru \\ ${ }^{2}$ Department of Chemical Engineering Processes and Apparatus. Kazan National Research Technological \\ University. Siberian tract, 68. Kazan, 420029. Tatarstan Republic. Russia. \\ Phone:+7 (843)231-40-32.E-mail: iraida@kstu.ru
}

Keywords: water cut oils, gate valve, regulatory authority, injection well.

*Supervising author; ${ }^{+}$Corresponding author

\begin{abstract}
A modification of the gate valve with the added throttle valve as a second stage of controlling the flow of water to install it at the mouth of the injection well. An experimental study of the hydrodynamic characteristics of a gate valve with a butterfly valve at the mouth of an injection well at a cluster pumping station under various operating modes of the valve by replacing built-in fittings and inlet pressure has been carried out. The study showed the effectiveness of the added valve in the design of the valve, the valve will minimize unproductive injection of water into injection wells and reduce the water content of the oil produced, and consequently, reduce the cost of oil refining. In comparison with gate valves, in which the linear dependence of the flow rate on the inlet pressure can be traced, the gate valve under study with a valve will more stably maintain the flow rate and pressure at a set level with increasing pressure in the conduit. A study of the hydrodynamic characteristics of the modified valve in the Fluent utility package Ansys with the help of the built models in Compass 3D was carried out. As a result of modeling the hydrodynamics of water in the channels of the valve under study, the calculated data of velocity fields and pressure distribution over the entire length of the models of valves with different input pressure were obtained. The dependences of the change in pressure and velocity along the length of the regulator, obtained by modeling the hydrodynamics of the flowing water in the valve, are confirmed by the obtained data in the experiment. The results of the calculation of the pressure change of the steady-state flow in the tube according to the Bernoulli equation for real liquids also coincide with the experimental data and data obtained in the simulation, which confirms the accuracy and reliability of all data. As a result of this work, a method was developed for calculating flowdifferential characteristics of a fluid flow regulator based on modeling in the ANSYS program. On the basis of experimentally confirmed studies of the characteristics of the fluid flow regulator, the developed method was tested for calculation errors. Based on the calculations, the choice of the optimal central hole in the interchangeable choke is made and the spring is selected for the calculated range of pressure changes.
\end{abstract}

\section{References}

[1] Ya.F. Magaril, A.A. Nazarov, Ya.S. Shpaner, R.G. Gimranov. Special torch heads. Chemical and Petroleum Engineering. 2009. Vol.45. No.1-2. P.13-14.

[2] A.L. Akhmadiev, V.P. Matveev, A.A. Nazarov, A.I. Giniyatulin. A mathematical model of heating of a reaction mixture in the process of vacuum de hydrogenation of hydrocarbons. Chemical and Petroleum Engineering. 2013. Vol.48. No.9-10. P.618-620.

[3] A.A. Nazarov, S.I. Ponikarov, K.A. Petlin. Mathematical model of gas-dynamic and heat exchange processes of hydrocarbon vacuum dehydration. Bulletin of Kazan Technological University. 2018. Vol.21. No.10. P.153-156. (russian)

[4] A.A. Nazarov, S.I. Ponikarov, K.A. Petlin. Numerical study of gasodynamic and heat exchange processes and testing of the mathematical model by comparison with experimental data. Bulletin of Kazan Technological University. 2018. Vol.21. No.11. P.157-161. (russian)

[5] A.A. Nazarov. Vacuum dehydration. Chemical and Petroleum Engineering. 2012. No.2. P.25. (russian) 
A.I. Nurmukhametov, A.Sh. Bicbulatov, and A.A. Nazarov

[6] A.A. Nazarov, V.P. Matveev, S.I. Ponikarov, K.A. Petlin. Vacuum dehydration of hydrocarbon raw material in chemical and petrochemical industry. Bulletin of Kazan Technological University. 2018. Vol.21. No.4. P.107-110. (russian)

[7] P.V. Osipov, G.V. Bulidorova, S.V. Krupin. Increased oil recovery, optimization of injection technology in the injection well of liquid glass with a water-soluble polymer NaКМЦ and restoration of the $\mathrm{NaOH}$ solution of its original reservoir characteristics in cases of unsuccessful waterproofing. Butlerov Communications. 2002. Vol.2. No.9. P.45-51. RIO: jbc-02/02-2-9-45 